\title{
Association of cortisol serum levels as a prognostic factor in threat of pre-term birth
}

\author{
Francisco R. Joya ${ }^{1 *}$, Jose Daniel Gonzalez Ortiz ${ }^{2}$, Cindy R. Bandala ${ }^{3}$, \\ Marlene de la Peña Gutierrez ${ }^{4}$, Maria Isabel Tolentino Sosa ${ }^{5}$, Arturo B. Vilchis ${ }^{6}$
}

\begin{abstract}
${ }^{1}$ Department of Gynecology and Obstetrics, Postgraduate School of Naval Sanity, ${ }^{2}$ Navy Medical School of Medicine, ${ }^{4}$ Department of Gynecology and Obstetrics, Maternal-Fetal Medicine, ${ }^{5}$ Department of Gynecology and Obstetrics, Gynecological Urology, ${ }^{6}$ Department of Gynecology and Obstetrics, Universidad Naval and the Centro Médico Naval, Secretaría de Marina Armada de México, Semar, Mexico

${ }^{3}$ INP Researcher, National Institute of Rehabilitation, Mexico
\end{abstract}

Received: 10 December 2020

Revised: 02 February 2021

Accepted: 02 February 2021

*Correspondence:

Dr. Francisco R. Joya,

E-mail: sw-ank@hotmail.com

Copyright: ( ) the author(s), publisher and licensee Medip Academy. This is an open-access article distributed under the terms of the Creative Commons Attribution Non-Commercial License, which permits unrestricted non-commercial use, distribution, and reproduction in any medium, provided the original work is properly cited.

\section{ABSTRACT}

Background: Prematurity is one of the leading causes of death in children. In Mexico there is a frequency of $12 \%$ of preterm birth and this leads to significant maternal-fetal complications comprising $31.5 \%$ of neonatal morbidity and mortality. The patient who receives obstetric care in the gynecology service at the naval medical center requires prevention, diagnosis and treatment of threat of preterm birth to reduce perinatal and neonatal complications. Serum cortisol levels was determined as a prognostic factor for the threat of preterm birth in patients with obstetric care at the Naval Medical Center, it is a relatively easy parameter to obtain and would support a timely treatment.

Methods: We used a quantitative, non-experimental, retrospective descriptive study of 30 patients with risk factors to develop preterm birth threats in gynecology service of the naval medical center from January to December 2018, which were taken 3 milliliters of peripheral blood to measure serum cortisol concentrations for later analysis. For statistical analysis of the present study, it was used Shapiro Wilk test. Likewise, Pearson's test was performed to measure the degree of association between the dependent and independent variable. Student's t-test was implemented to compare cortisol levels of pregnant women.

Results: A total of 30 patients of these were analyzed, the mean age was 30.4 years (SD \pm 5.184$)$. The gestation weeks the average value was 30.63 weeks $(\mathrm{SD} \pm 4.781)$. A student $\mathrm{t}$ test was performed where the cortisol values of pregnant women were compared with an average value of 2,586 (95\% CI 0.45-472) and a t value $=2,476$ and a $p=0.019$ lower value of the significance value of 0.05 rejecting the null hypothesis. Which indicates that cortisol levels can be used as a predictive marker of the threat of preterm birth, considering it as an independent factor for this situation to occur in pregnant patients. The variables of the cortisol level and the weeks of gestation Pearson=-0.061 and a significance of $\mathrm{p}=0.747$ were correlated (there being no strong enough relationship between the study variables). Regarding the triggers, it is observed that the highest factor was for urinary tract infection $40 \% \mathrm{n}=12$, abnormal uterine activity $20 \% \mathrm{n}=6$, followed by premature membrane rupture $16.7 \% \mathrm{n}=5$.

Conclusions: The risk factors associated with the threat of preterm birth can be multiple, encompassing them in three important areas such as socioeconomic, psycho-emotional and clinicopathological, of the latter, nine of which are most frequent in our population are urinary infection, abnormal uterine activity and premature rupture of membranes. Regarding the association of cortisol levels as a prognostic factor for the threat of preterm birth taking it into account as an independent factor, it can be concluded that it is not statistically significant, however, according to what is reported in the literature, It should be considered as one of the multiple risk factors, considering this timely premise to boost the development of new research in the field.

Keywords: Preterm birth, Cortisol, Uterine activity, Prognostic factor 


\section{INTRODUCTION}

The World Health Organization reported that every year about 15 million babies are born in the world before they reach term, that is, more than one in 10 births. Approximately one million premature children die each year due to complications in childbirth. Many of the premature babies who survived suffer some kind of lifelong disability, particularly learning-related disabilities and visual and hearing problems. Worldwide prematurity is the leading cause of mortality in children under five years. In almost all countries with reliable data, premature birth rates are increasing. ${ }^{1}$ In a study conducted by Minguet-Romero and collaborators at the Mexican social security institute (IMSS) during the period 2007-2012 in the second and third level hospitals it was observed that in a second level of care there were 188,715 (6.8\%) born preterm while a third level of care (high specialty medical units) there were 51,635 (13.7\%) born preterm. When considering all births, they concluded that an incidence of $7.7 \%$ was found nationwide during the period studied. ${ }^{2}$

The threat of preterm birth is defined by one that takes place from week 20.1 and 36.6 weeks gestation with a weight equal to or greater than $500 \mathrm{gm}$ and that breathes or shows signs of life. Convincing clinical and research evidence suggests that a series of processes lead to a common final pathway that leads to spontaneous premature delivery. The 4 main processes are: premature activation of the maternal or fetal hypothalamus-pituitaryadrenal axis, inflammatory response/exaggerated infection, detachment (deciduous hemorrhage), and pathological uterine distention. ${ }^{3}$ Early signs and symptoms of preterm birth include; low and constant low back pain, uterine contractions of mild intensity at irregular intervals and blood flow. However, these signs and symptoms are specific and often occur in women as the pregnancy ends. ${ }^{4}$ Factors associated with preterm birth include: maternal reproductive factors such as a history of preterm birth and maternal age; maternal disorders such as infections, anemia, hypertension, preeclampsia/eclampsia, pulmonary and cardiovascular disorders, diabetes; different maternal lifestyles such as physical activity antecedent of substance abuse or smoking, diet, weight and stress; cervical, uterine and placental factors such as short cervix, cervical surgery, uterine malformations and vaginal bleeding; multiple gestation; Fetal factors such as presence of congenital anomalies, growth restriction, fetal infections and fetal stress. ${ }^{5}$

The presence of a preterm birth threat of one or more of the following symptoms and signs is considered: clinically documented uterine contractions (1/10 min, 4/20 min or $6 / 60 \mathrm{~min}$ or more); cervical dilation equal to or greater than $2 \mathrm{~cm}$; and cervical erasure equal to or greater than $80 \%$. Ultrasound evaluation of cervical length and fetal fibronectin test have a high negative predictive value; therefore, the unique use of both allows to determine what type of patients will not require tocolysis. Amniocentesis can be used in women with a threat of preterm birth to assess fetal lung maturity and intra-amniotic infection. ${ }^{3}$

Fetal fibronectin will be performed between weeks 24 to 34 of gestation in patients at risk of preterm birth. Cervical length measurement will be performed between weeks 20.1 to 34 of gestation in patients at risk of preterm birth. Fibronectin is an extracellular matrix glycoprotein found in amniotic membranes, decidua and cytotrophoblast. It can be found in cervical and vaginal secretions in all pregnancies, but elevated levels (>50 $\mathrm{ng} / \mathrm{ml}$ at 22 weeks gestation) have been associated with an increased risk of having preterm birth. ${ }^{6}$ The goal of tocolytics is the inhibition of uterine dynamics to complete the fetal pulmonary maturation and/or neuroprophylaxis. If uterine dynamics is restarted, its reintroduction will be reassessed. $^{7}$

Virtually any type of stress, whether physical or neurogenic, causes an immediate and noticeable increase in ACTH secretion by the adenohypophysis, followed a few minutes after a considerable secretion of cortisol by the adrenal cortex. The types of stress that increase cortisol release are: severe trauma, infection, heat or cold and surgery.

When a tissue is damaged due to trauma, a bacterial infection or any other cause, it usually becomes inflamed. Cortisol exerts preventive effects of inflammation: stabilizes lysosomal membranes as it increases the resistance to rupture of intracellular lysosome membranes, therefore, in the damaged cells there is a significant decrease in the release of almost all proteolytic enzymes that indicate inflammation, reduces the permeability of the capillaries. This decrease in permeability prevents the release of plasma into the tissues, cortisol decreases leukocyte migration to the inflamed area and phagocytosis of damaged cells, it inhibits the immune system and greatly reduces the multiplication of lymphocytes, especially $\mathrm{T}$ lymphocytes. In turn, the lower amount of $\mathrm{T}$ lymphocytes and antibodies in the inflamed area dampens tissue reactions that would otherwise promote inflammation, and fever decreases, especially since it reduces the release of interleukin 1 by leukocytes, one of the main stimulators of the hypothalamic thermoregulatory system. ${ }^{8}$ The objective of the present study is to determine the association between serum cortisol levels as a prognostic factor for threatened preterm birth in patients with obstetric care at the Naval Medical Center. Likewise, it was considered to describe the sociodemographic characteristics of patients with threatened preterm delivery. Simultaneously considering the temporality of the study, perinatal complications were identified in the patients diagnosed with preterm delivery.

\section{METHODS}

Patients with abnormal uterine activity and threat of preterm birth were captured in the area of toco-surgery and outpatient consultation of the naval medical center who 
were informed verbally and in writing about the use of cortisol in blood for such a previous thesis study. Signature of the informed consent was taken. Subsequently, $3 \mathrm{ml}$ of peripheral blood was extracted from patients with threat of preterm birth and abnormal uterine activity, serum cortisol concentrations in $\mathrm{mg} / \mathrm{dl}$ were measured; said samples were processed inside the hospital laboratory, as well as the use of reagents from the area.

The samples were collected with the use of material from the laboratory area of the naval medical center which has the professional staff for this task. The data obtained from each patient through the HIS system of the naval medical center were recorded in an electronic database for subsequent statistical analysis.

The sample population is patients with threatened preterm birth who attend the gynecology service of the hospital General Naval de Alta Especialidad.

\section{Inclusion criteria}

Patients who want to participate in the study by signing the consent under the information for taking a blood sample to quantify serum cortisol levels, patients with threatened preterm labor, patients with abnormal uterine activity, and patients with urinary tract infection, stress, trauma that could trigger threatened preterm labor were included in the study.

\section{Exclusion criteria}

Patients with a diagnosis of threatened preterm birth plus added systemic disease such as: systemic arterial hypertension, chronic kidney failure, type 1 and 2 diabetes mellitus, autoimmune disease and non-physiological anemia, patients without a diagnosis of threatened preterm labor, and patients who decide not to participate in the research study were excluded.

\section{Elimination criteria}

Patients who decide not to continue with the study and patients who withdraw their consent form under information.

Measures of central tendency and dispersion (quantitative variables), frequencies and percentages (qualitative variables) were determined. The Kolmogorov-Smirnov test (for distribution of quantitative variables), student's T (to compare two averages) and Pearson's correlation (to relate two quantitative variables) were applied. A value of $\mathrm{p}<0.05$ was taken as statistical significance. The data analysis was carried out with the SPSS version 19 program.

\section{RESULTS}

A total of 30 patients of these were analyzed, the mean age was 30.4 years $(S D \pm 5.184)$ minimum of 20 years and maximum of 40 years. The gestation weeks the average value was 30.63 weeks ( $\mathrm{SD} \pm 4.781)$ minimum of 22 weeks and maximum of 36 weeks (Table 1).

Regarding cortisol levels, the average value was 17.59 $(\mathrm{SD} \pm 5.72)$, minimum of 9 and maximum of 32. A Shapiro Wilk normality test was performed where the value of $p$ was $>0.05$, thus demonstrating that the study population is a normal population.

A student t test was performed where the cortisol values of pregnant women were compared with an average value of 2,586 (95\% CI $0.45-472)$ and a $t$ value $=2,476$ and a $\mathrm{p}=0.019$ lower value of the significance value of 0.05 rejecting the null hypothesis. Which indicates that cortisol levels can be used as a predictive marker of the threat of preterm birth, considering it as an independent factor for this situation to occur in pregnant patients (Table 2).

Regarding the triggers, it is observed that the highest factor was for urinary tract infection $40 \% \mathrm{n}=12$, abnormal uterine activity $20 \% \mathrm{n}=6$, followed by premature membrane rupture $16.7 \% \mathrm{n}=5$ (Figure 1 ).

Also, the averages of the weeks of gestation, cortisol, triglyceride, cholesterol, uric acid and cortisol levels evaluated in patients with and without risk age for preterm birth (Table 3).

The correlations of the weeks of gestation and the evaluation of cortisol, triglycerides, cholesterol and uric acid, evaluated in patients at risk of premature delivery.

We observed that women of risk age for preterm birth had a strong positive correlation trend with cortisol $(\mathrm{r}=+0.77$, $\mathrm{p}=0.07)$ and a strong negative correlation $(\mathrm{r}=-0.88$, $\mathrm{p}=0.02$ ) of the weeks of pregnancy with the concentration of cholesterol in the blood (Table 4).

Table 1: Relative risk of abnormal Doppler indices with adverse perinatal outcome.

\begin{tabular}{|llllll|}
\hline Descriptiv-e statistics & $\mathbf{N}$ & Mínimum & Maximum & Media & Standard deviation \\
\hline Age & 30 & 20 & 40 & 30.40 & 5.184 \\
\hline Cortisol levels & 30 & 9 & 32 & 17.59 & 5.720 \\
\hline Gestational age & 30 & 22 & 36 & 30.63 & 4.781 \\
\hline N & 30 & & & & \\
\hline
\end{tabular}


Table 2: Single sample test.

\begin{tabular}{|c|c|c|c|c|c|c|}
\hline \multirow{3}{*}{ Test } & \multicolumn{6}{|c|}{ Test value $=15$} \\
\hline & \multirow{2}{*}{$\mathbf{t}$} & \multirow{2}{*}{ gl } & \multirow{2}{*}{$\begin{array}{l}\text { Sig. } \\
\text { (bilateral) }\end{array}$} & \multirow{2}{*}{$\begin{array}{l}\text { Measurement } \\
\text { differences }\end{array}$} & \multicolumn{2}{|c|}{$95 \%$ confidence interval of difference } \\
\hline & & & & & Inferior & Superior \\
\hline Cortisol levels & 2.476 & 29 & 0.019 & 2.586 & 0.45 & 4.72 \\
\hline
\end{tabular}

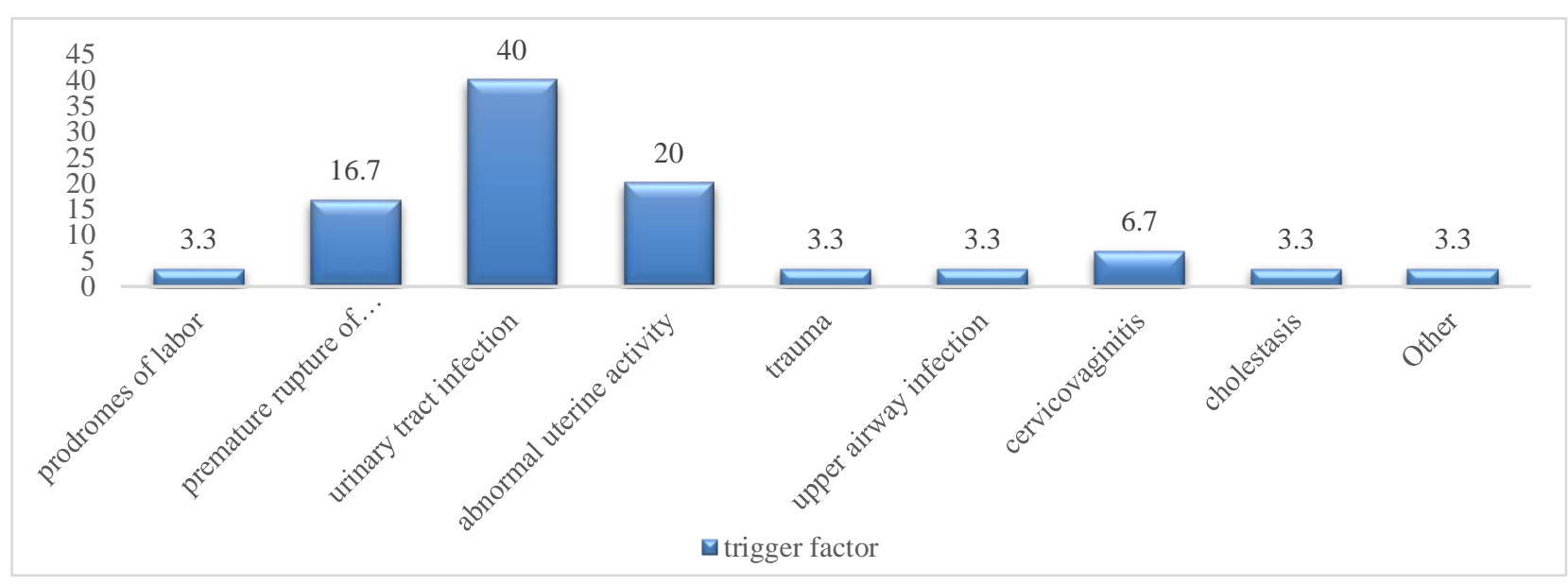

Figure 1: Triggering factor.

Table 3: Comparison of the weeks of gestation, cortisol concentration, uric acid, triglycerides and cholesterol in patients with and without risk age for preterm birth triggering factor.

\begin{tabular}{|llll|}
\hline \multirow{2}{*}{ Comparison of parameters } & \multicolumn{2}{l|}{ Age of risk for preterm birth } & Valor $\mathbf{~}$ \\
\hline Gestational age (weeks) & Si Media \pm DE & No Media $\pm \mathbf{D E}$ & 0.26 \\
\hline Cortisol & $28.67 \pm 5.64$ & $31.13 \pm 4.54$ & 0.54 \\
\hline Triglycerides (mg/dl) & $18.88 \pm 5.26$ & $17.26 \pm 5.88$ & 0.49 \\
\hline Cholesterol (mg/dl) & $258.17 \pm 60.52$ & $229.08 \pm 97.95$ & 0.56 \\
\hline Uric acid (mg/dl) & $226.50 \pm 25.71$ & $217.29 \pm 56.43$ & 0.37 \\
\hline
\end{tabular}

Table 4: Correlation in between the weeks of gestation and the levels of cortisol, triglycerides, cholesterol and uric acid in patients with risk age for preterm birth.

\begin{tabular}{|llll|}
\hline Correlation & r (valor p) & Correlation & r $($ valor p) \\
\hline Cortisol & $+0.77(0.07)$ & Triglycerides $(\mathrm{mg} / \mathrm{dl})$ & $+0.21(0.68)$ \\
\hline Uric acid $(\mathbf{m g} / \mathbf{d l})$ & $+0.54(0.25)$ & Cholesterol $(\mathrm{mg} / \mathrm{dl})$ & $-0.88(0.02 *)$ \\
\hline
\end{tabular}

\section{DISCUSSION}

The present study analyzed 30 patients during pregnancy between 20.1 and 36.6 weeks of gestation, finding an average of 30.63 weeks of gestation with a standard deviation of +4.781 , the chronological age of the patients ranged in a range of 20 to 40 years with an average of 30.40 and a standard deviation of +5.184 , with respect to cortisol levels levels were found around 9 to $32 \mu \mathrm{g} / \mathrm{dl}$ with an average of $17.59 \mu \mathrm{g} / \mathrm{dl}$ and a standard deviation of $+5,720$. All this analyzed in a period of 9 months.

In this study the risk factors associated with the development of preterm birth were analyzed, finding that the most frequent factor is urinary tract infection with $40 \%$ $(n=12)$, followed by abnormal uterine activity with $20 \%$ $(n=6)$ and thirdly the premature rupture of membranes with $16.7 \%(n=5)$; although in this study the psychoemotional factors of the patients were not considered as reported in the work carried out by Caroline Liliecreutz in 2016 in 340 women, where they show that $54 \%$ of them experienced some factor associated with stress which caused them to give to light your products prematurely. ${ }^{9}$

In research conducted by Bandoli and collaborators where a case-control study was conducted with a sample of 993 women who were measured cortisol from serum samples collected as part of the routine prenatal examination, where it was assessed whether the change of the adjusted cortisol measurement differed according to gestational age at the time of delivery or the subtype of premature delivery by multivariable linear regression. As a result, an inverse 
association between cortisol and the gestational age category was obtained. Among deliveries before 37 weeks, the adjusted mean cortisol change values were the highest for premature rupture of membranes, followed by premature delivery and premature labor induced by the patient. In conclusion, cortisol continues to be of interest as a marker of future premature births. The increase should be explored with additional biomarkers. ${ }^{10}$

In the present investigation it was determined that there is no significant association between the increase in cortisol levels and risk to trigger preterm labor independently of the rest of the risk factors, as observed in the Pearson association analysis, $\mathrm{p}=0.747$, association power of $\mathrm{r} 2=0.061$. These results contrast with the work presented by Rabiepoor in 2019, analyzing 110 pregnant patients divided into 2 groups (28 and 32, 32 and 36 weeks of gestation) where each patient presented some stress situation during the development of their pregnancy which originated an elevation of cortisol levels, both in the mother and in her product, we understand as a factor that triggers stress any situation outside the physiological state of the pregnant woman, this difference between both studies may be due to the amount of patient that were analyzed while in the first one there were only 30 patients in the second jurisdiction 110, which allows the statistical analysis to be more significant for the association between the analyzed factors (preterm birth and elevated cortisol levels), so that It can be assumed entirely in our study that there is no true association.

Carry out research considering as variables the socioeconomic factors (place of residence, socioeconomic status, exposure to prolonged working hours), psychoemotional (states of stress, depression and anxiety) and clinicopathological (pre-eclampsia, prediabetes, gestational diabetes, chronic hypertension, gestational hypertension, hypothyroidism, hyperthyroidism, multiple deeds). Consider the waking sleep status of patients that could be included in future research. Measure cortisol levels in patients who come to their prenatal control routinely and not only in those suspected of threatening preterm birth.

\section{CONCLUSION}

According to the results obtained in the present investigation, we can conclude the following: the risk factors associated with threatened preterm birth can be multiple, encompassing them in three important areas such as socioeconomic, psycho-emotional and clinicopathological, of the latter, nine were analyzed of which those that present the highest frequency in our population are urinary tract infection, abnormal uterine activity, and premature rupture of membranes. Regarding the association of cortisol levels as a prognostic factor for the threat of preterm birth, taking it into account as an independent factor, it can be concluded that it is not statistically significant, however, according to what has been reported in the literature, It should be considered as one of the multiple risk factors, considering this opportune premise to promote the development of new research on the matter.

\section{Funding: No funding sources \\ Conflict of interest: None declared}

Ethical approval: The study was approved by the Institutional Ethics Committee

\section{REFERENCES}

1. World Health Organization. 2017. Avaliable at: http://www.who.int/mediacentre/factsheet/fs363/es.2 017. Accessed on 26 August 2020.

2. Minguet-Romero R, Cruz-Cruz P, Del R, Ruíz-Rosas RA, Hernández-Valencia M. Incidencia de nacimientos pretérmino en el IMSS (2007-2012). Ginecologia y Obstetricia de Mexico. 2014;82(7):465-71.

3. Instituto Mexicano del Seguro Social. Guía De Práctica Clínica GPC Prevención, Diagnóstico y Tratamiento Del Parto Pretérmino. 2017. Availabale at: http://www.imss.gob.mx/profesionales-salud/gpc. Accessed on 26 August 2020.

4. Alonso-López G, Rosales-Ortíz JS. Diagnóstico Y Manejo Del Parto Pretérmino. Colegio Mexicano de Especialistas En Ginecologia y Obstetricia, A.C. 2010;129-49.

5. Lilliecreutz C, Larén J, Sydsjö G, Josefsson A. Effect of maternal stress during pregnancy on the risk for preterm birth. BMC Pregnancy Childbirth. 2016;16:75

6. Son M, Miller ES. Seminars in Perinatology Predicting preterm birth : Cervical length and fetal fi bronectin. 2017.

7. Prematuritat U, Maternofetal SDM, Cobo S, Ferrero MP. Protocolo: Amenaza de Parto Pretérmino. Hospital Clinic Barcelona. 2014;1-11.

8. Hall JE. Tratado de fisiología médica (13th ed). Elsevier. 2016.

9. Lilliecreutz C, Larén J, Sydsjö G, Josefsson A. Effect of maternal stress during pregnancy on the risk for preterm birth. BMC Pregnancy and Childbirth. 2016;16:5.

10. Bandoli G, Jelliffe-pawlowski LL, Feuer SK, Oltman SP, Paynter R, Ross KM, et al. HHS Public Access. 2018;38(8):973-81.

Cite this article as: Joya FR, Ortiz JDG, Bandala CR, Gutierrez MP, Sosa MIT, Vilchis AB.

Association of cortisol serum levels as a prognostic factor in threat of pre-term birth. Int J Reprod Contracept Obstet Gynecol 2021;10:825-9. 